say; the extract prepared from the roots of $P$. hoppeana subsp. testimonialis was found to be the most active one with $\mathrm{IC}_{50}$ values of $0,231 \mathrm{M}$. The MDA level of this sample was found as $3.91 \mathrm{nmol} / \mathrm{ml}$. Phytochemical screening of the tested extracts was performed by RP-HPLC using some flavonoids and phenolic acids as standards.

References: (1) Wojdylo A., Oszmianski J., Czemerys R. Antioxidant and phenolic compounds in 32 selected herbs. Food Chem. 105: 940-949 (2007). (2) Erdogan-Orhan I., Sever-Yılmaz B., Altun L., Saltan G. Radical quenching activity, fer- ric reducing antioxidant power and ferrous ionchelating capacity of 16 Ballota species and their total phenol and flavonoid contents. J. Med. Food 13 (6): 1537-1543 (2010). (3) Pietta P. G. Flavonoids as antioxidants. J. Nat. Prod. 63: 10351042 (2000). (4) Stanojevic L., Stankovic M., Nikolic V., Nicolic L., Ristic D., CanadanovicBrunet J., Tumbas V. Antioxidant activity and total phenolic and flavonoid contents of Hieracium pilosella L. extracts. Sensors, 9: 5702-5714 (2009).

\title{
DEVELOPMENT AND VALIDATION OF TLC METHOD FOR THE IDENTIFICATION OF EUCALYPTUS LEAVES
}

\section{() Evdokimova O.V., Obukhova V. V., Kuzminova L. V.}

JSC “Krasnogorskleksredstva”, Krasnogorsk, Moscow region, Russia

According to "Krasnogorskleksredstva" House monograph 42-8000-06 "Eucalyptus leaves" the determination of lipophilic compounds in this herbal medicinal product is carried out by TLC method. This method requires only one reference substance - Sudan III. But it is more reasonable to use two reference substances in TLC analysis that allows to evaluate the suitability of chromatographic system. The purpose of our study was to develop and validate a new identification method for Eucalyptus leaves with use of two reference substances. The study object was Eucalyptus leaves; TLC was chosen as an analytical method for identification of lipophilic compounds profile in the samples. In order to harmonize with leading Pharmacopoeias the mobile phase was changed from toluene - ethyl acetate (95:5) to toluene - ethyl acetate (90:10; according to European Pharmacopoeia 7.001/2008:1320) and the plates were changed from TLC-P-A (Sorbfil, Russia) to TLC Silica gel 60 (aluminium sheets, Merck, Germany). Solutions of Sudan Red G and Sudan III were used as reference solutions. Anisaldehyde solution was used for detection. The following zones were present in daylight in the chromatograms obtained with the reference solutions: the zone with red color ( $R_{f}$ approx. 0.4 that was accepted as $R_{s}=1.0$, due to Sudan Red $G$ ) and the zone with blue or blue-violet color ( $R_{s}$ approx. 1.4 , due to Sudan III). The following zones of lipophilic compounds were present in daylight in the chromatograms obtained with the test solution: 3 zones with violet color $\left(R_{s}\right.$ (by Sudan Red $G$ ) approx. $0.2 ; 0.6 ; 2.0)$; zone with dark violet color on start line and others zones could be present. Method validation included evaluation of chromatographic system specificity and suitability. The method specificity was evaluated by coincidence of the different batches chromatographic profiles by the main zones and by compliance of abovementioned profiles with the test solution chromatogram description. The method validation was performed on 6 industrial batches. Chromatographic profiles of the different batches have coincided and been compliant with the test solution chromatogram description. The resolution between zones of Sudan Red $G\left(R_{s}\right.$ approx. 1.0) and Sudan III ( $R_{s}$ approx. 1.4$)$ in the chromatogram obtained with the reference solutions has been chosen as a chromatographic system suitability index. The resolution value between the chosen zones must not be less than 1.5. The resolution values that had been calculated by the chromatograms obtained from different batches satisfied the method requirements. The suggested method can be used for identification of Eucalyptus leaves in routine analyses. This method has been included into the draft version of "Krasnogorskleksredstva" House monograph on Eucalyptus leaves. 